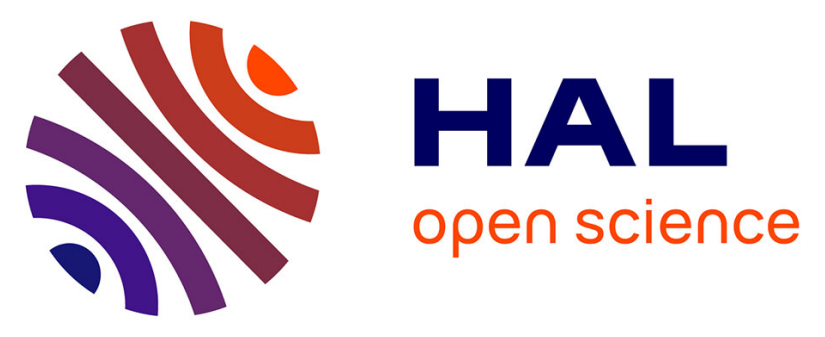

\title{
Carotid Artery Stiffness and Incident Depressive Symptoms: The Paris Prospective Study III
}

Thomas T. van Sloten, Pierre Boutouyrie, Muriel Tafflet, Lucile Offredo, Frédérique Thomas, Catherine Guibout, Rachel E. Climie, Cédric Lemogne, Bruno Pannier, Stéphane Laurent, et al.

\section{To cite this version:}

Thomas T. van Sloten, Pierre Boutouyrie, Muriel Tafflet, Lucile Offredo, Frédérique Thomas, et al.. Carotid Artery Stiffness and Incident Depressive Symptoms: The Paris Prospective Study III. Biological Psychiatry, 2019, 85, pp.498 - 505. 10.1016/j.biopsych.2018.09.018 . hal-03486659

\section{HAL Id: hal-03486659 \\ https://hal.science/hal-03486659}

Submitted on 20 Dec 2021

HAL is a multi-disciplinary open access archive for the deposit and dissemination of scientific research documents, whether they are published or not. The documents may come from teaching and research institutions in France or abroad, or from public or private research centers.
L'archive ouverte pluridisciplinaire HAL, est destinée au dépôt et à la diffusion de documents scientifiques de niveau recherche, publiés ou non, émanant des établissements d'enseignement et de recherche français ou étrangers, des laboratoires publics ou privés.

\section{(ㄷ)(1) $\$$}

Distributed under a Creative Commons Attribution - NonCommerciall 4.0 International 


\section{Carotid artery stiffness and incident depressive symptoms: The Paris Prospective Study 3}

Thomas T van Sloten, MD, PhD ${ }^{\mathrm{a}, \mathrm{b}, \mathrm{c}, \mathrm{d}}$, Pierre Boutouyrie, MD, $\mathrm{PhD}^{\mathrm{a}, \mathrm{c}, \mathrm{e}}$, Muriel Tafflet, MSc $\mathrm{c}^{\mathrm{a}, \mathrm{b}}$, Lucile Offredo, $\mathrm{MSc}^{\mathrm{a}, \mathrm{b}}$, Frédérique Thomas, $\mathrm{PhD}^{\mathrm{f}}$, Catherine Guibout, $\mathrm{PhD}^{\mathrm{a}, \mathrm{b}}$, Rachel E Climie, PhD ${ }^{\mathrm{a}, \mathrm{b}, \mathrm{g}, \mathrm{h}}, \mathrm{C}$ Lemogne, MD, PhD, ${ }^{\mathrm{a}, \mathrm{h}, \mathrm{i}}$ Bruno Pannier, $\mathrm{MD}^{\mathrm{f}}$, Stéphane Laurent, MD, $\mathrm{PhD}^{\mathrm{a}, \mathrm{c}, \mathrm{e}}$, Xavier Jouven, $\mathrm{MD}, \mathrm{PhD}^{\mathrm{a}, \mathrm{b}}$, Jean-Philippe Empana, $\mathrm{MD}, \mathrm{PhD}^{\mathrm{a}, \mathrm{b}}$

a. Université Paris Descartes, Sorbonne Paris Cité, Faculté de Médecine, Paris, France.

b. INSERM, UMR-S970, Paris Cardiovascular Research Center, Department of Epidemiology, Paris, France.

c. INSERM, UMR-S970, Paris Cardiovascular Research Center, Department of Arterial Mechanics, Paris, France.

d. Cardiovascular Research Institute Maastricht and Department of Internal Medicine, Maastricht University Medical Centre, Maastricht, the Netherlands

e. AP-HP, Georges Pompidou European Hospital, Department of Pharmacology, Paris, France.

f. Preventive and Clinical Investigation Center, Paris, France.

g. Menzies Institute for Medical Research, University of Tasmania, Hobert, Australia

h. AP-HP, Georges Pompidou European Hospital, Department of Psychiatry, Paris, France

i. INSERM, U894, Psychiatry and Neuroscience Center, Paris, France

Short/running title: Carotid stiffness and incident depressive symptoms

Keywords: epidemiology, longitudinal studies, vascular depression, aging, arterial stiffness, late-life depression

Word count abstract: 246

Word count main text: 3,255

Figures: 2

Tables: 1

Supplemental information: 2 tables, 1 figure, expanded methods

\section{Corresponding author:}

Thomas van Sloten, INSERM U970, Paris Cardiovascular Center, 56 rue Leblanc, 75015

Paris, France, E: t.van.sloten@mumc.nl; T: +33-153987961, Fax: +33-153987954 


\begin{abstract}
Background: Arterial stiffness may contribute to late-life depression via cerebral microvascular damage, but evidence is scarce. No longitudinal study has evaluated the association between arterial stiffness and risk of depressive symptoms. We therefore investigated the association between carotid artery stiffness and incident depressive symptoms in a large community-based cohort study.
\end{abstract}

Methods: This longitudinal study included 7,013 participants (mean age 59.7 (SD 6.3); $35.8 \%$ women) free of depressive symptoms at baseline. Carotid artery stiffness (highresolution echotracking) was determined at baseline. Presence of depressive symptoms was determined at baseline and at 4 and 6 years of follow-up, and was defined as a score $\geq 7$ on the validated Q2DA questionnaire and/or new use of antidepressant medication. Logistic regression and generalized estimating equations were used.

Results: In total, 6.9\% $(\mathrm{n}=484)$ of the participants had incident depressive symptoms. Individuals in the lowest tertile of carotid distensibility coefficient (indicating greater carotid artery stiffness) compared to those in the highest tertile had a higher risk of incident depressive symptoms (odds ratio: $1.43,95 \%$ confidence interval: 1.10-1.87), after adjustment for age, sex, living alone, education, lifestyle, cardiovascular risk factors and baseline Q2DA scores. Results were qualitatively similar when we used carotid Young's elastic modulus as a measure of carotid stiffness instead of carotid distensibility coefficient, and when we used generalized estimating equations instead of logistic regression.

Conclusions: Greater carotid stiffness is associated with a higher incidence of depressive symptoms. This supports the hypothesis that carotid stiffness may contribute to the development of late-life depression. 


\section{Introduction}

By 2020, depression and depressive symptoms will be the largest contributors to global disability, after heart disease, in individuals aged $\geq 65$ years $(1,2)$. Major depression occurs in $2 \%$ of adults aged 65 years or older, and its prevalence rises with increasing age. In addition, $10 \%$ to $15 \%$ of older adults have clinically significant depressive symptoms, even in the absence of major depression (3). Late-life depressive symptoms are associated with lower quality of life (4), functional impairment (5), 1.5- to 2-fold higher mortality risk $(6,7)$, and 2fold higher incidence of cardiovascular disease (8). However, current antidepressant medications are less effective $(9,10)$ and have more side-effects $(11)$ in older compared to younger patients. More than $50 \%$ of older patients do not respond to such treatment (12). New effective interventions for prevention and treatment of late-life depression and depressive symptoms, therefore, need to be developed, which requires a better understanding of late-life depression risk factors.

Arterial stiffness, which can be quantified non-invasively by measuring local distensibility of the carotid artery $(13,14)$, has been associated with a higher risk of cerebrovascular damage (15-17), and may contribute to the development of depressive symptoms. Although stiffening of arteries is an age-related phenomenon, it can occur in younger individuals, and, thus, arterial stiffness may contribute to depressive symptoms across the lifespan (18).

Stiffening of large arteries impairs their cushioning function and increases pressure and flow pulsatility. This increased pulsatile load may transmit distally into the cerebral circulation and, thereby, contribute to cerebrovascular damage (19). Cerebrovascular damage, in turn, may predispose to depression via disruption of frontal and subcortical structures involved in mood regulation $(20,21)$. Most previous studies (22-25), but not all $(26,27)$, have found an 
association between arterial stiffness and depressive symptoms (22-24) and depression (2325). However, these studies were all cross-sectional by design, precluding any conclusions about a temporal association between arterial stiffness and depressive symptoms.

We therefore evaluated the longitudinal association between carotid stiffness and incident depressive symptoms in a large community-based cohort study of individuals aged 50-75 years at baseline. 


\section{Methods and Materials}

\section{Study design}

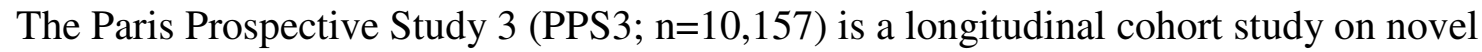
markers for phenotypes of cardiovascular disease. The design and main objectives of PPS3 have been described previously (28). In brief, individuals aged between 50-75 years were recruited at the Centre d'Investigations Préventives et Cliniques (IPC), a large preventive medical center in Paris (France), between June, 2008 and June, 2012. The IPC is one of the largest preventive medical centers in France and conducts free medical examinations $(20,000-$ 25,000 examinations/year) among all working and retired employees and their families. The IPC is subsidized by the French National Insurance System for salaried workers. The Ethics Committee of the Cochin Hospital (Paris, France) approved the study. In addition, PPS3 was registered in the World Health Organization international clinical trial registry platform (NCT00741728).

\section{Carotid stiffness}

Carotid stiffness was determined using a high-resolution echotracking system (Artlab, Esaote, Maastricht, the Netherlands), as described previously (29). All measurements were done in a core-lab by trained vascular technicians unaware of the participants' clinical status. Briefly, we used a $10 \mathrm{MHz} 128$ transducer linear array probe and performed the measurements on a 4 $\mathrm{cm}$ segment of the right common carotid artery $(1 \mathrm{~cm}$ proximal to the bifurcation) throughout the cardiac cycle for 6 seconds. The system allows real-time radiofrequency signal analysis with operator-independent determination of carotid diameter and mean intima-media thickness. Distension was measured on 14 lines at high-pulsed radiofrequency $(600 \mathrm{~Hz})$. The 
carotid distensibility coefficient (DC) was calculated according to the following equation: $\triangle \mathrm{LCSA} / \mathrm{LCSA} \cdot \mathrm{PP}$, where LCSA is diastolic lumen cross-sectional area, $\triangle \mathrm{LCSA}$ is stroke change in lumen area, and PP is local pulse pressure estimated from the carotid distension waveform. In addition, Young's elastic modulus (YEM) was calculated as $3 \cdot(1+\mathrm{LCSA} /$ WCSA) / DC, where WCSA is wall cross-sectional area. Carotid DC represents the elasticity of the artery as a whole, whereas carotid YEM represents the stiffness of the arterial wall material. These indices are correlated, but carotid DC varies with carotid diameter and intimamedia thickness, whereas carotid YEM is independent of artery structure. Please note that lower values of carotid DC, but higher values of carotid YEM reflect greater carotid stiffness. The reproducibility of carotid artery stiffness measurements has been demonstrated previously (30). A description of the data quality control of these measurements in PPS3 is provided in the online supplemental material.

\section{Depressive symptoms}

Depressive symptoms were assessed at baseline and at 4 and 6 years of follow-up using the 13-item Questionnaire of Depression $2^{\text {nd }}$ version, Abridged (QD2A) (31). The QD2A is a validated French questionnaire specifically designed for assessment of depressive symptoms in community studies and has a high internal consistency $(\alpha=0.91)$ (the questionnaire is provided in the supplemental material) (31). Participants were required to give a yes/no answer to each of the 13 items regarding their current emotional state. Response options can generate a continuous score ranging from 0 (no symptoms) to 13 (all symptoms). A QD2A score $\geq 7$ indicates a high probability for a major depressive disorder (sensitivity: $81 \%$, specificity: 96\%) (31). In addition, information on the use of antidepressants (ATC codes: N06AA-NO6AX) was obtained at baseline, and at 4 and 6 years of follow-up. At baseline, a medical doctor checked current medication during a face-to-face interview with participants. 
At follow-up, use of antidepressant medication was assessed by questionnaire. Presence of depressive symptoms was defined as a QD2A cut-off score of $\geq 7$ or use of antidepressant medication (irrespective of indication). Prior history of depression or any other psychiatric disease was self-reported in the general health questionnaire (see below).

\section{Covariates}

Self-administered questionnaires were used to obtain information on education level, smoking behavior (categories: never, former and current), physical activity, dietary habits, alcohol consumption, perceived stress and medical history. We divided education level into three categories: 1) low (no or primary education); 2) intermediate (secondary education), and 3) high (higher education or university). The validated Baecke score was used to estimate overall physical activity (higher scores indicating higher levels of physical activity) (32). Dietary habits were evaluated using a semi-quantitative validated 18-item food frequency questionnaire (33). Dietary habits were classified as defined by the American Heart Association as ideal, intermediate or poor, as described previously (34). Alcohol consumption was categorized as never, 1-2 or $>2$ units/day. Perceived stress was measured with the 4-item Perceived Stress Scale (35). Presence of any sleep disorder (self-reported), excessive daytime sleepiness (as determined by the Epworth sleepiness scale (36)), proxy for sleep-disordered breathing (based on questions of the Berlin questionnaire, as described previously (37)), and insomnia symptoms (using questions from the Pittsburgh sleep quality index (38)) were also measured. Blood pressure was recorded using an Omron $705 \mathrm{C}$ oscillometric device and an appropriate sized cuff after 10 min of supine rest. Hypertension was defined by a blood pressure of $\geq 140 / 90 \mathrm{mmHg}$ and/or use of antihypertensive medication. Fasting glucose and lipid levels were measured, as described previously (28). Prior cardiovascular disease was defined by a self-reported history of stroke, myocardial infarction and/or angina pectoris. 
Diabetes was defined by use of glucose-lowering medication and/or a fasting blood glucose $\geq 7 \mathrm{mmol} / \mathrm{L}$.

\section{Analytic sample}

Of the 10,157 participants included in PPS3, 46 had missing data on baseline depressive symptoms, 877 had missing data on arterial stiffness, and another 184 had missing data on potential confounders. In the remaining 9,050 participants, 1,172 (13.0\%) had missing data on depressive symptoms at both follow-up examinations. In the remaining 7,878 participants, we excluded 865 individuals $(11.0 \%)$ with depressive symptoms at baseline (i.e. QD2A score $\geq 7$ and/or use of antidepressant medication). Thus, the final study sample consisted of 7,013 participants. This comprised 2,866 individuals with data on one follow-up examination (either at 4 year, $\mathrm{n}=2,665$, or at 6 year, $\mathrm{n}=201$ ) and 4,147 individuals with data on two follow-up examinations at the time of analysis. Participants with missing data for the present analysis, compared to those included in the analysis, were more likely to be younger (59.3 years versus 59.7 years), less educated (primary school or less: $40.7 \%$ versus $29.0 \%$ ) and current smokers (19.9\% versus $13.6 \%)$, and to have diabetes $(6.2 \%$ versus $3.8 \%)$, prior cardiovascular disease (2.9\% versus $1.8 \%)$, hypertension (41.7\% versus $35.3 \%)$ and a higher body mass index (25.7 $\mathrm{kg} / \mathrm{m}^{2}$ versus $25.1 \mathrm{~kg} / \mathrm{m}^{2}$; all P-values <.05).

\section{Statistical analysis}

We report the results comparing those individuals in the highest sex-specific tertile of carotid stiffness to those in the lowest sex-specific tertile of carotid stiffness. We used logistic regression to estimate odds ratios (ORs) and 95\% confidence intervals (95\%CIs) for the association between baseline carotid DC or carotid YEM and incident depressive symptoms. In addition, we used generalized estimating equations (GEE) with an exchangeable 
correlation structure and robust standard errors to estimate odds ratios (ORs) and 95\%CIs for the association between baseline carotid DC and carotid YEM and presence of depressive symptoms at 4 and/or 6 years at follow-up. GEE is a method for longitudinal data analysis that takes into account the correlation of repeated measurements within individuals over time (39). We adjusted the analyses for the following potential confounders selected based on previous literature (22-27): age at entry, sex, living alone, education level, smoking, systolic and diastolic blood pressure, heart rate, diabetes, total/HDL cholesterol ratio, prior cardiovascular disease, body mass index, physical activity and use of antihypertensive and/or lipid-modifying medication at baseline (model 1), and additionally for baseline Q2DA scores (model 2).

We examined interactions with age and sex, but none were statistically significant (all Pvalues for interaction >.10). Results are therefore reported without stratification for these factors.

We did several additional analyses to test the robustness of our findings: 1) we repeated the analyses with depressive symptoms at follow-up defined as only a Q2DA score $\geq 7$ as the outcome, irrespective of use of antidepressant medication; 2) we repeated the analyses after excluding individuals with prior cardiovascular disease or incident cardiovascular disease during follow-up; 3 ) we additionally adjusted the results for baseline dietary habits and alcohol consumption; 4) we additionally adjusted for perceived stress at baseline; 5) we repeated the analyses with adjustment for fasting glucose instead of diabetes; 6) we additionally adjusted for sleep disturbances, including any sleep disorder, excessive daytime sleepiness, proxy for sleep-disordered breathing and insomnia symptoms; 7) we repeated the analyses in individuals without a self-reported prior history of depression or any other 
psychiatric disease; and 8) we repeated the analyses in individuals with complete data on depressive symptoms at both follow-up examinations. 


\section{Results}

The mean age of the study population at baseline was 59.7 (SD 6.3) years, and 35.8\% were women (Table 1). In total, 6.9\% $(n=484)$ of the participants had incident depressive symptoms, of whom $72.1 \%(n=349)$ had a Q2DA score $\geq 7$ and $31.6 \%(n=153)$ had started using antidepressant medication. The mean time between the baseline and first follow-up examination was 4.1 years (SD 0.2), and between baseline and the second follow-up examination 6.1 years (SD 0.2).

Results of the logistic regression analysis showed that individuals in the lowest tertile of carotid DC (for women: $<17.510^{-3} / \mathrm{kPa}$, and for men: $<18.010^{-3} / \mathrm{kPa}$ ) compared to those in the highest tertile (for women: $>24.710^{-3} / \mathrm{kPa}$, and for men: $>24.310^{-3} / \mathrm{kPa}$ ) had a higher risk of incident depressive symptoms (OR 1.40, 95\%CI 1.08-1.81), after adjustment for potential confounders (Figure 1). Further adjustment for baseline Q2DA scores did not materially change this result (Figure 1). The ORs and 95\% CIs for all factors contained in the regression model are provided in the supplemental material Table S1. In addition, individuals in the highest tertile of carotid YEM (for women: $>0.50410^{-3 *} \mathrm{kPa}$, and for men: $>0.53610^{-3 *} \mathrm{kPa}$ ) compared to those in the lowest tertile (for women: $<0.36310^{-3 *} \mathrm{kPa}$, and for men: $<0.38910^{-}$ $3 * \mathrm{kPa}$ ) had a higher risk of incident depressive symptoms (OR 1.28, 1.00-1.66), after adjustment for potential confounders and baseline Q2DA scores (Figure 1). Similarly, results of the longitudinal analyses (GEE) showed that individuals with lower carotid DC or higher carotid YEM had higher odds of depressive symptoms at follow-up, although the results for carotid YEM were not statistically significant (fully adjusted ORs: for carotid DC 1.35, 95\%CI 1.04-1.76, and for carotid YEM 1.23, 95\%CI 0.96-1.57; Supplemental Figure S1). 
The results of the additional analyses are shown in Figure 2 and Table S2. Results were qualitatively similar when we repeated the analyses with depressive symptoms at follow-up defined only as a Q2DA score $\geq 7$, irrespective of use of antidepressant medication; when we excluded individuals with prior cardiovascular disease or incident cardiovascular events during follow-up (total $n=252$ ); after additional adjustments for dietary habits and alcohol consumption, or perceived stress, or fasting glucose instead of diabetes; after exclusion of individuals with a prior history of depression or any other psychiatric disease $(n=520)$; or when we repeated the analysis in individuals with complete data on depressive symptoms at both follow-up examinations ( $\mathrm{n}=4,147)$ (Figure 2). In addition, results did not materially change after adjustments for presence of any sleep disorder, excessive daytime sleepiness, proxy for sleep-disordered breathing or insomnia symptoms (supplemental Table S2). 


\section{Discussion}

In the present large community-based cohort study, greater carotid stiffness was associated with a higher incidence of depressive symptoms, after accounting for socio-economic status, lifestyle and cardiovascular risk factors. To our knowledge, this is the first longitudinal study to date demonstrating that greater carotid stiffness is a risk factor for incident depressive symptoms.

The present longitudinal study extends previous population-based studies, including the Age, Gene / Environment susceptibility (AGES)-Reykjavik study (n=2,058) (22), Rotterdam study $(n=3,704)(23)$ and Maastricht study $(n=2,757)(24)$, that evaluated the cross-sectional association between arterial stiffness and depressive symptoms. These studies found that greater aortic or carotid stiffness is associated with presence of depressive symptoms (22-24) and depression $(23,24)$, but their cross-sectional design did not allow conclusions about the direction of this association.

Stiffening of the carotid artery (or other elastic arteries for which the carotid artery may serve as a proxy) may contribute to cerebral microvascular damage and subsequent depressive symptoms via an increased pulsatile load on the cerebral microcirculation $(19,40)$. This increased load may directly cause cerebral ischemia and hemorrhage. Further, the increased pulsatile load may induce a hypertrophic remodeling response and rarefaction of small cerebral arteries, which, in turn, may lead to chronic ischemia $(19,40)$. It is likely that ischemia may damage frontal and subcortical structures or their connecting pathways involved in mood regulation and, hence, may lead to depressive symptoms $(20,21,41)$. In accordance, a previous meta-analysis found that greater arterial stiffness is associated with various MRI markers of cerebral small vessel disease (i.e. white matter hyperintensities, 
cerebral microbleeds and lacunes) (42), and such MRI markers have been shown to be associated with a higher incidence of depressive symptoms (43). Furthermore, cross-sectional data from the AGES-Reykjavik Study (22) showed that the association between greater arterial stiffness and presence of depressive symptoms was in part explained, or mediated, by markers of cerebral small vessel disease, i.e. white matter hyperintensities and lacunes.

However, other underlying mechanisms may explain the observed associations in the present study. First, other factors may be independently related to both carotid stiffness and depressive symptoms, such as stress, unhealthy lifestyle habits and cardiovascular disease. However, the associations between carotid stiffness and incident depressive symptoms were independent of perceived stress, physical activity, smoking, dietary habits and alcohol consumption. Furthermore, results did not materially change after excluding individuals with cardiovascular disease. Second, the association between arterial stiffness and incident depressive symptoms may exist because late-life depressive symptoms represent an early manifestation of (vascular) dementia (44). However, we had no available information on cognitive performance or dementia in the present study, and this issue requires further investigation. Third, it has been suggested that associations between cerebrovascular damage and depression may be (partially) attributable to apathy (45). Apathy overlaps with depression but may be a distinct syndrome (46). In the present study, we did not measure apathy, and this issue also requires further study. Fourth, early adversity may explain part of the observed associations, because early adversity has been related to both arterial stiffness (47) and depression (48). However, no data on early adversity was available in our study, and this requires further study. Fifth, other biological mechanisms may underlie both arterial stiffness and depressive symptoms. For instance, oxidative stress and low-grade inflammation are related to arterial stiffness $(49,50)$, cerebral white matter integrity $(51)$, cerebral small vessel 
damage (52), and depression (53). In addition, recent studies found that lower brain-derived neurotrophic factor (BDNF), an important risk factor for depression, is related to greater carotid intima-media thickness (54) and higher pulse pressure (a surrogate measure for greater arterial stiffness) (55). However, data on oxidative stress, low-grade inflammation, and BDNF were not available in the present study.

The present results did not differ according to age and sex. In accordance, most previous studies on arterial stiffness and depression $(22,23,26)$, that were all cross-sectional in design, did not find an interaction for sex. Only one previous study, The Maastricht Study (24), evaluated interaction with age. In contrast to our results, this study found a stronger association between aortic stiffness and presence of depression in younger ( $<60$ years) as compared to older individuals ( $\geq 60$ years). This inconsistent finding between The Maastricht Study and our study may be due to differences in the source of populations investigated (preventive care center vs. population-based), arterial stiffness measurement (carotid artery stiffness vs. aortic stiffness), study design (longitudinal vs. cross-sectional) or the result of the play of chance, and requires further study.

From a clinical point of view, the association between carotid stiffness and incident depressive symptoms is important because it suggests that arterial stiffness is a target for prevention strategies of vascular-related late-life depression. Intervention studies suggest that lifestyle modifications, such as weight loss, exercise and dietary modifications, may have a beneficial effect on both arterial stiffness $(56,57)$ and depression $(58)$. In addition, drugs, such as angiotensin receptor-2 agonists (e.g. compound 21), renin-angiotensin aldosterone system (RAAS) inhibitors and statins, may lower arterial stiffness, possibly beyond any blood 
pressure-lowering effects $(56,57)$. Pharmaco-epidemiologic data indicate that RAAS inhibitors (59) and statins (60) may also have antidepressant properties.

Strengths of the present study include the state-of-the-art imaging of the carotid artery to estimate carotid stiffness, the longitudinal design and the wide set of potential confounders in a large community-based study population.

The present study has also several limitations. First, depressive symptoms were assessed by a self-reported questionnaire, and not by a structured interview. Therefore, there was no available information on clinical depression. Nevertheless, the sensitivity and specificity of questionnaire measures compared with a depression diagnosis based on a structured interview are high (31). Furthermore, depressive symptoms, even in the absence of a diagnosis of major depression, are associated with 1.5 - to 2 -fold higher mortality $(6,7)$. Second, misclassification of incident depressive symptoms may have occurred because antidepressant medication can also prescribed for conditions other than depression. However, the results were qualitatively similar when Q2DA scores alone were used as the outcome. Third, we had no information on presence of depressive symptoms in the intervals between follow-up examinations, and this may have led to an underestimation of the association between carotid stiffness and incident depressive symptoms. Finally, our study population was relatively healthy and included mostly individuals of Caucasian ethnicity. The results may therefore not be generalizable to clinical samples and other ethnicities.

In conclusion, the present study shows that greater carotid stiffness is associated with a higher incidence of depressive symptoms. This suggests that carotid stiffness may contribute to the development of late-life depression. 


\section{Acknowledgements}

PPS3 was supported by grants from The National Research Agency, the Research Foundation for Hypertension, the Research Institute in Public Health, and the Region Ile de France

(Domaine d'Intérêt Majeur). RC is supported by a Prestige and Marie Curie Fellowship, a Lefoulon Delalande Fellowship, a High Blood Pressure Research Council of Australia Franco-Aus exchange grant and a L'Institute Servier travel grant. TVS is supported by a National Research Agency grant and a L'Institute Servier travel grant. 


\section{Disclosures}

All authors report no biomedical financial interests or potential conflicts of interest. 


\section{References}

1. Chapman DP, Perry GS (2008): Depression as a major component of public health for older adults. Prev Chronic Dis. 5:A22.

2. Depression and Other Common Mental Disorders: Global Health Estimates. Geneva: World Health Organization; 2017. Licence: CC BY-NC-SA 3.0 IGO.

3. Kok RM, Reynolds CF, 3rd (2017): Management of Depression in Older Adults: A Review. JAMA. 317:2114-2122.

4. Chachamovich E, Fleck M, Laidlaw K, Power M (2008): Impact of major depression and subsyndromal symptoms on quality of life and attitudes toward aging in an international sample of older adults. Gerontologist. 48:593-602.

5. Lyness JM, Heo M, Datto CJ, Ten Have TR, Katz IR, Drayer R, et al. (2006):

Outcomes of minor and subsyndromal depression among elderly patients in primary care settings. Ann Intern Med. 144:496-504.

6. Barefoot JC, Schroll M (1996): Symptoms of depression, acute myocardial infarction, and total mortality in a community sample. Circulation. 93:1976-1980.

7. Penninx BW, Geerlings SW, Deeg DJ, van Eijk JT, van Tilburg W, Beekman AT (1999): Minor and major depression and the risk of death in older persons. Arch Gen Psychiatry. 56:889-895.

8. Nicholson A, Kuper H, Hemingway H (2006): Depression as an aetiologic and prognostic factor in coronary heart disease: a meta-analysis of 6362 events among 146538 participants in 54 observational studies. Eur Heart J. 27:2763-2774.

9. Tedeschini E, Levkovitz Y, Iovieno N, Ameral VE, Nelson JC, Papakostas GI (2011): Efficacy of antidepressants for late-life depression: a meta-analysis and meta-regression of placebo-controlled randomized trials. J Clin Psychiatry. 72:1660-1668. 
10. Calati R, Salvina Signorelli M, Balestri M, Marsano A, De Ronchi D, Aguglia E, et al. (2013): Antidepressants in elderly: metaregression of double-blind, randomized clinical trials. J Affect Disord. 147:1-8.

11. Coupland C, Dhiman P, Morriss R, Arthur A, Barton G, Hippisley-Cox J (2011): Antidepressant use and risk of adverse outcomes in older people: population based cohort study. BMJ. 343:d4551.

12. Thomas A, O'Brien JT (2015): Management of late-life depression: a major leap forward. Lancet. 386:2374-2375.

13. Safar ME ORM (2006): Arterial stiffness in hypertension. Amsterdam: Elsevier. 14. Laurent S, Cockcroft J, Van Bortel L, Boutouyrie P, Giannattasio C, Hayoz D, et al. (2006): Expert consensus document on arterial stiffness: methodological issues and clinical applications. Eur Heart J. 27:2588-2605.

15. van Sloten TT, Sedaghat S, Laurent S, London GM, Pannier B, Ikram MA, et al. (2015): Carotid stiffness is associated with incident stroke: a systematic review and individual participant data meta-analysis. J Am Coll Cardiol. 66:2116-2125.

16. Rosano C, Watson N, Chang Y, Newman AB, Aizenstein HJ, Du Y, et al. (2013): Aortic pulse wave velocity predicts focal white matter hyperintensities in a biracial cohort of older adults. Hypertension. 61:160-165.

17. Ding J, Mitchell GF, Bots ML, Sigurdsson S, Harris TB, Garcia M, et al. (2015):

Carotid arterial stiffness and risk of incident cerebral microbleeds in older people: the Age, Gene/Environment Susceptibility (AGES)-Reykjavik study. Arterioscler Thromb Vasc Biol. $35: 1889-1895$.

18. Goldstein BI, Carnethon MR, Matthews KA, McIntyre RS, Miller GE, Raghuveer G, et al. (2015): Major Depressive Disorder and Bipolar Disorder Predispose Youth to 
Accelerated Atherosclerosis and Early Cardiovascular Disease: A Scientific Statement From the American Heart Association. Circulation. 132:965-986.

19. Mitchell GF (2008): Effects of central arterial aging on the structure and function of the peripheral vasculature: implications for end-organ damage. J Appl Physiol. 105:16521660.

20. Alexopoulos GS, Meyers BS, Young RC, Campbell S, Silbersweig D, Charlson M (1997): 'Vascular depression' hypothesis. Arch Gen Psychiatry. 54:915-922.

21. Taylor WD, Aizenstein HJ, Alexopoulos GS (2013): The vascular depression hypothesis: mechanisms linking vascular disease with depression. Mol Psychiatry. 18:963974.

22. van Sloten TT, Mitchell GF, Sigurdsson S, van Buchem MA, Jonsson PV, Garcia ME, et al. (2016): Associations between arterial stiffness, depressive symptoms and cerebral small vessel disease: cross-sectional findings from the AGES-Reykjavik Study. J Psychiatry Neurosci. 41:162-168.

23. Tiemeier H, Breteler MM, van Popele NM, Hofman A, Witteman JC (2003): Late-life depression is associated with arterial stiffness: a population-based study. J Am Geriatr Soc. $51: 1105-1110$

24. Onete V, Henry RM, Sep SJS, Koster A, van der Kallen CJ, Dagnelie PC, et al. (2018): Arterial stiffness is associated with depression in middle-aged men - the Maastricht Study. J Psychiatry Neurosci. 43:111-119.

25. Paranthaman R, Greenstein AS, Burns AS, Cruickshank JK, Heagerty AM, Jackson A, et al. (2010): Vascular function in older adults with depressive disorder. Biol Psychiatry. 68:133-139. 
26. Lewis TT, Sutton-Tyrrell K, Penninx BW, Vogelzangs N, Harris TB, Vaidean GD, et al. (2010): Race, psychosocial factors, and aortic pulse wave velocity: the Health, Aging, and Body Composition Study. J Gerontol A Biol Sci Med Sci. 65:1079-1085.

27. Seldenrijk A, van Hout HP, van Marwijk HW, de Groot E, Gort J, Rustemeijer C, et al. (2011): Depression, anxiety, and arterial stiffness. Biol Psychiatry. 69:795-803.

28. Empana JP, Bean K, Guibout C, Thomas F, Bingham A, Pannier B, et al. (2011): Paris Prospective Study III: a study of novel heart rate parameters, baroreflex sensitivity and risk of sudden death. Eur J Epidemiol. 26:887-892.

29. Proust C, Empana JP, Boutouyrie P, Alivon M, Challande P, Danchin N, et al. (2015): Contribution of Rare and Common Genetic Variants to Plasma Lipid Levels and Carotid Stiffness and Geometry: A Substudy of the Paris Prospective Study 3. Circ Cardiovasc Genet. 8:628-636.

30. Girerd X, Giannattasio C, Moulin C, Safar M, Mancia G, Laurent S (1998):

Regression of radial artery wall hypertrophy and improvement of carotid artery compliance after long-term antihypertensive treatment in elderly patients. J Am Coll Cardiol. 31:10641073.

31. Pichot P. A self-report inventory on depressive symptomatology (QD2) and its abridged form (QD2). In Assessment of Depression. Springer. 1986:108-122.

32. Baecke JA, Burema J, Frijters JE (1982): A short questionnaire for the measurement of habitual physical activity in epidemiological studies. Am J Clin Nutr. 36:936-942.

33. Lasfargues G, Vol S, Le Clesiau H, Bedouet M, Hagel L, Constans T, et al. (1990): [Validity of a short self-administered dietary questionnaire compared with a dietetic interview]. Presse Med. 19:953-957. 
34. Gaye B, Mustafic H, Laurent S, Perier MC, Thomas F, Guibout C, et al. (2016): Ideal Cardiovascular Health and Subclinical Markers of Carotid Structure and Function: The Paris Prospective Study III. Arterioscler Thromb Vasc Biol. 36:2115-2124.

35. Lesage FX, Berjot S, Deschamps F (2012): Psychometric properties of the French versions of the Perceived Stress Scale. Int J Occup Med Environ Health. 25:178-184.

36. Johns MW (1991): A new method for measuring daytime sleepiness: the Epworth sleepiness scale. Sleep. 14:540-545.

37. Lisan Q, Tafflet M, Charles MA, Thomas F, Boutouyrie P, Guibout C, et al. (2018):

Self-reported body silhouette trajectories across the lifespan and excessive daytime sleepiness in adulthood: a retrospective analysis. The Paris Prospective Study III. BMJ Open. 8:e020851. 38. Buysse DJ, Reynolds CF, 3rd, Monk TH, Berman SR, Kupfer DJ (1989): The Pittsburgh Sleep Quality Index: a new instrument for psychiatric practice and research. Psychiatry Res. 28:193-213.

39. Twisk JWR. Applied Longitudinal Data Analysis for Epidemiology: A Practical Guide. Cambridge, United Kingdom: Cambridge University; 2003.

40. van Sloten TT, Schram MT, Adriaanse MC, Dekker JM, Nijpels G, Teerlink T, et al. (2014): Endothelial dysfunction is associated with a greater depressive symptom score in a general elderly population: the Hoorn Study. Psychol Med. 44:1403-1416.

41. Krishnan KR, Hays JC, Blazer DG (1997): MRI-defined vascular depression. Am J Psychiatry. 154:497-501.

42. van Sloten TT, Protogerou AD, Henry RM, Schram MT, Launer LJ, Stehouwer CD (2015): Association between arterial stiffness, cerebral small vessel disease and cognitive impairment: A systematic review and meta-analysis. Neurosci Biobehav Rev. 53:121-130. 
43. Rensma SP, van Sloten TT, Launer LJ, Stehouwer CDA (2018): Cerebral small vessel disease and risk of incident stroke, dementia and depression, and all-cause mortality: A systematic review and meta-analysis. Neurosci Biobehav Rev.

44. Singh-Manoux A, Dugravot A, Fournier A, Abell J, Ebmeier K, Kivimaki M, et al. (2017): Trajectories of Depressive Symptoms Before Diagnosis of Dementia: A 28-Year Follow-up Study. JAMA Psychiatry. 74:712-718.

45. Hollocks MJ, Lawrence AJ, Brookes RL, Barrick TR, Morris RG, Husain M, et al. (2015): Differential relationships between apathy and depression with white matter microstructural changes and functional outcomes. Brain. 138:3803-3815.

46. Marin RS (1991): Apathy: a neuropsychiatric syndrome. J Neuropsychiatry Clin Neurosci. 3:243-254.

47. Su S, Wang X, Kapuku GK, Treiber FA, Pollock DM, Harshfield GA, et al. (2014): Adverse childhood experiences are associated with detrimental hemodynamics and elevated circulating endothelin-1 in adolescents and young adults. Hypertension. 64:201-207.

48. Edwards VJ, Holden GW, Felitti VJ, Anda RF (2003): Relationship between multiple forms of childhood maltreatment and adult mental health in community respondents: results from the adverse childhood experiences study. Am J Psychiatry. 160:1453-1460.

49. Patel RS, Al Mheid I, Morris AA, Ahmed Y, Kavtaradze N, Ali S, et al. (2011):

Oxidative stress is associated with impaired arterial elasticity. Atherosclerosis. 218:90-95.

50. van Bussel BC, Schouten F, Henry RM, Schalkwijk CG, de Boer MR, Ferreira I, et al. (2011): Endothelial dysfunction and low-grade inflammation are associated with greater arterial stiffness over a 6-year period. Hypertension. 58:588-595.

51. Versace A, Andreazza AC, Young LT, Fournier JC, Almeida JR, Stiffler RS, et al. (2014): Elevated serum measures of lipid peroxidation and abnormal prefrontal white matter 
in euthymic bipolar adults: toward peripheral biomarkers of bipolar disorder. Mol Psychiatry. 19:200-208.

52. Wardlaw JM, Smith C, Dichgans M (2013): Mechanisms of sporadic cerebral small vessel disease: insights from neuroimaging. Lancet Neurol. 12:483-497.

53. Miller AH, Maletic V, Raison CL (2009): Inflammation and its discontents: the role of cytokines in the pathophysiology of major depression. Biol Psychiatry. 65:732-741.

54. Hatch JK, Scola G, Olowoyeye O, Collins JE, Andreazza AC, Moody A, et al. (2017): Inflammatory Markers and Brain-Derived Neurotrophic Factor as Potential Bridges Linking Bipolar Disorder and Cardiovascular Risk Among Adolescents. J Clin Psychiatry. 78:e286e293.

55. Lee IT, Sheu WH, Lee WJ, Chen DY (2018): Serum brain-derived neurotrophic factor predicting reduction in pulse pressure after a one-hour rest in nurses working night shifts. Sci Rep. 8:5485.

56. Nilsson PM, Boutouyrie P, Cunha P, Kotsis V, Narkiewicz K, Parati G, et al. (2013): Early vascular ageing in translation: from laboratory investigations to clinical applications in cardiovascular prevention. J Hypertens. 31:1517-1526.

57. Mitchell GF (2014): Arterial stiffness and hypertension. Hypertension. 64:13-18. 58. Sarris J, O'Neil A, Coulson CE, Schweitzer I, Berk M (2014): Lifestyle medicine for depression. BMC Psychiatry. 14:107.

59. Boal AH, Smith DJ, McCallum L, Muir S, Touyz RM, Dominiczak AF, et al. (2016): Monotherapy With Major Antihypertensive Drug Classes and Risk of Hospital Admissions for Mood Disorders. Hypertension. 68:1132-1138.

60. Kohler O, Gasse C, Petersen L, Ingstrup KG, Nierenberg AA, Mors O, et al. (2016): The Effect of Concomitant Treatment With SSRIs and Statins: A Population-Based Study. Am J Psychiatry. 173:807-815. 


\section{Figure legends}

Figure 1. Association between carotid distensibility coefficient (DC; tertile 1 vs. tertile 3) and Young's elastic modulus (YEM; tertile 3 vs. tertile 1) and incident depressive symptoms.

Model 1 adjusted for age, sex, living alone, education level, smoking, systolic and diastolic blood pressure, heart rate, diabetes, total/HDL cholesterol ratio, prior cardiovascular disease, body mass index, physical activity, and use of antihypertensive and/or lipid-modifying medication. Model 2 additionally adjusted for baseline Q2DA score.

Figure 2. Additional analyses. Association between carotid distensibility coefficient (DC; tertile 1 vs. tertile 3) and Young's elastic modulus (YEM; tertile 3 vs. tertile 1) and incident depressive symptoms

1) Depressive symptoms at follow-up defined only as a Q2DA score $\geq 7$, irrespective of use of antidepressant medication; 2) Individuals excluded with prior cardiovascular disease (CVD) or incident cardiovascular disease during follow-up $(n=252)$; 3) Results additionally adjusted for dietary habits (ideal, intermediate or poor dietary habits as defined by the American Heart Association) and alcohol consumption (0, 0-2 and $>2$ units/day) (data missing in $n=1,003) ; 4$ ) Results additionally adjusted for perceived stress; 5) Results adjusted for fasting glucose instead of diabetes; 6) Individuals excluded with a self-reported history of prior depression or any other psychiatric disease $(\mathrm{n}=520)$; and 7) Analyses repeated in individuals with complete data on depressive symptoms at both follow-up examinations $(n=4,147)$. All results are adjusted for age, sex, living alone, education level, smoking, systolic and diastolic blood pressure, heart rate, diabetes, and diastolic blood pressure, heart rate, diabetes, total/HDL cholesterol ratio, prior cardiovascular disease, body mass index, physical activity, use of antihypertensive and/or lipid-modifying medication, and baseline Q2DA scores. 
Table 1. Baseline characteristics of the total study population, and according to incident depressive symptoms

\begin{tabular}{ccc} 
Total study & Without incident & With incident \\
population & depressive & depressive \\
$(\mathrm{n}=7,013)$ & symptoms & symptoms \\
& $(93.1 \%, \mathrm{n}=6,529)$ & $(6.9 \%, \mathrm{n}=484)$ \\
\hline
\end{tabular}

Baseline characteristics

Age (years)

$59.7(6.3)$

$59.7(6.3)$

$59.9(6.7)$

Women

$35.8(2,509)$

$34.6(2,258)$

$52.1(251)$

Education

Low

$28.4(1,989)$

$28.1(1,833)$

$32.2(156)$

Intermediate

$29.3(2,058)$

$29.3(1,915)$

$29.5(143)$

High

$42.3(2,966)$

$42.6(2,781)$

$38.2(185)$

Living alone

$23.0(1,616)$

$22.5(1,470)$

30.2 (146)

Self-reported history of prior

$7.4(520)$

$6.5(424)$

$19.8(96)$

depression or any other psychiatric

disease

Smoking

Never

$53.0(3,719)$

$53.1(3,469)$

$51.7(250)$

Former

$34.0(2,384)$

$34.0(2,221)$

33.7 (163)

Current

$13.0(910)$

12.9 (839)

$14.7(71)$

Type 2 diabetes mellitus

$3.8(263)$

$3.6(236)$

$5.6(27)$

Prior cardiovascular disease

1.7 (116)

$1.6(104)$

$2.5(12)$

Hypertension

$35.1(2,464)$

$35.2(2,300)$

33.9 (164)

Systolic blood pressure (mmHg)

131 (16)

131 (16)

129 (16)

$76(9)$

76 (9)

75 (10)

$61(9)$

$61(9)$

$62(9)$

Heart rate (bpm)

$25.1(3.5)$

$25.1(3.5)$

$25.1(4.1)$

Physical activity (Baecke score)

$6.9(1.5)$

$6.9(1.5)$

$6.7(1.5)$

Total cholesterol (mg/dL)

$221(35)$

$221(35)$

$222(39)$

HDL cholesterol (mg/dL)

$58(15)$

$58(15)$

60 (16)

Antihypertensive medication

$14.5(1,016)$

14.4 (938)

$16.1(78)$

$13.4(941)$

$13.3(867)$

$15.3(74)$

Carotid stiffness

Distensibility coefficient $\left(10^{-3} / \mathrm{kPa}\right)$

$22.0(7.9)$

22.0 (7.9)

$21.6(8.1)$

Young's elastic modulus $\left(10^{-3 *} \mathrm{kPa}\right)$

$0.493(0.220)$

$0.492(0.217)$

$0.502(0.254)$

Data are mean (standard deviation) or \% (n) as appropriate. 


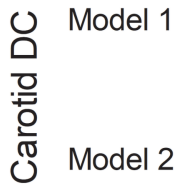

$1.40(1.08 ; 1.81)$

$\sum_{\Psi}$ Model 1

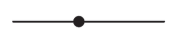

$1.43(1.10 ; 1.87)$

$1.27(0.99 ; 1.63)$

$1.28(1.00 ; 1.66)$

Чั Model 2

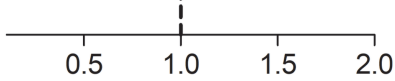

Odds ratio (95\% confidence interval) 
1. $Q D 2 A \geq 7$

Carotid DC

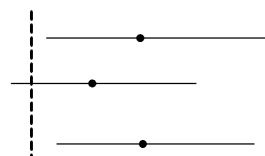

$1.42(1.05 ; 1.93)$

Carotid YEM

2. Exclusion of CVD

Carotid DC

Carotid YEM

3. Adjustment diet and alcohol

Carotid DC

Carotid YEM

\section{Adjustment stress}

Carotid DC

Carotid YEM

5. Adjustment fasting glucose

Carotid DC

Carotid YEM

6. Exclusion history psychiatric disease?

Carotid DC

Carotid YEM

7. Complete follow-up data

Carotid DC

Carotid YEM

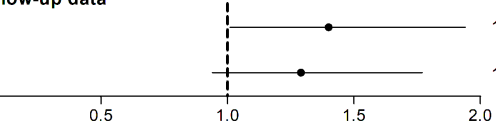

$1.23(0.92 ; 1.65)$

$1.44(1.09 ; 1.88)$

$1.30(1.00 ; 1.69)$

$1.54(1.15 ; 2.07)$

$1.34(1.02 ; 1.78)$

$1.39(1.07 ; 1.82)$

$1.25(0.97 ; 1.62)$

$1.43(1.10 ; 1.87)$

$1.28(0.99 ; 1.65)$

$1.45(1.08 ; 1.95)$

$1.23(0.93 ; 1.63)$

$1.43(1.06 ; 1.93)$

$1.24(0.92 ; 1.66)$

Odds ratio $(95 \%$ confidence interval) 